\title{
A call to action: developing and implementing a national action plan to improve bone health
}

\author{
L. G. Raisz • A. L. Elderkin • L. Schargorodski • \\ T. Hart $\cdot$ C. Waldman $\cdot$ T. King $\cdot$ A. S. Noonan
}

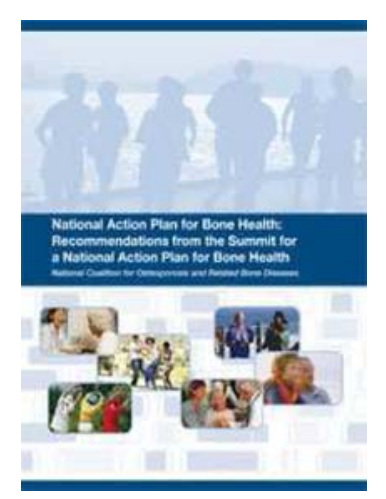

Received: 7 August 2009 /Accepted: 7 August 2009/Published online: 2 September 2009

(C) International Osteoporosis Foundation and National Osteoporosis Foundation 2009

Over the past 40 years, there have been important advances in our understanding of bone health and new methods to diagnose, prevent, and treat osteoporosis and other bone disorders. Our recognition that these advances

All authors belong to the Planning Committee of the Summit for a National Action Plan for Bone Health.

L. G. Raisz $(\bowtie)$

University of Connecticut Health Center,

263 Farmington Avenue,

Farmington, CT 06030, USA

e-mail: raisz@nso.uchc.edu

\section{A. L. Elderkin}

American Society for Bone and Mineral Research,

Washington, DC, USA

L. Schargorodski

National Osteoporosis Foundation,

Washington, DC, USA

T. Hart

Osteogenesis Imperfecta Foundation,

Gaithersburg, MD, USA

C. Waldman

The Paget Foundation,

New York, NY, USA

\section{T. King}

United States Bone and Joint Decade,

Chicago, IL, USA

\section{A. S. Noonan}

School of Public Health, Morgan State University,

Baltimore, MD, USA have not been adequately disseminated and more importantly have not been implemented was a major impetus for the Surgeon General's Report on Bone Health and Osteoporosis in 2004 [1]. This report outlined the key facts: Much of our current lifestyle is not conducive to bone health, there is an increasing risk of fragility fractures as our population ages, and this will have an enormous toll not only in terms of medical costs but also in morbidity and mortality. Moreover, both women and men of all races and ethnic groups are affected. Although osteoporosis and agerelated skeletal fragility have been the most extensively studied aspects of bone disease, studies on less common or even rare bone disorders have led to major advances in our understanding of bone health and disease.

Although there is a great deal more to be learned through basic and clinical research, we do know enough now to reverse or at least slow this trend. The problem has been that since the Surgeon General's Report was released in 2004, efforts to promote awareness, diagnosis, prevention, and treatment of osteoporosis and other metabolic bone disorders have been sporadic. It became clear that a coordinated effort among health care professionals, federal, state, and local government agencies, voluntary organizations, academics, communities, and the multiple components of the health care industry would be required to achieve a meaningful change.

In 2008, the National Coalition for Osteoporosis and Related Bone Diseases ("The Bone Coalition")-which includes the American Society for Bone and Mineral Research, National Osteoporosis Foundation, Osteogenesis Imperfecta Foundation, and The Paget Foundationconvened a 2-day summit to address this gap and develop 
Table 1 National Action Plan for Bone Health: priority areas and key strategies

Develop a bone health alliance - by forging a national alliance focused on bone health issues and increasing collaborations with organizations whose messages about healthy lifestyles dovetail with messages about improving bone health

Promote bone health and prevent disease — by building capacity of health care providers to focus on bone health across the lifespan; promoting adequate vitamin $\mathrm{D}$ and calcium intake, with a focus on revising the adequate intake level for vitamin $\mathrm{D}$; increasing advocacy activities at the federal and state levels; and developing standards or guidelines of care and performance measures

Improve diagnosis and treatment— by finding better ways to diagnose disease and assess risk, addressing issues of adequate reimbursement for diagnosis and evidence-based treatments, and focusing on fracture as a sentinel event in bone health management

Enhance research, surveillance, and evaluation — by continuing and expanding research now under way and finding ways to make more effective use of existing research; collecting and analyzing data to better understand who is at risk and to improve prevention, diagnosis, and treatment; and evaluating whether existing public education programs work

a national action plan. The summit's 150 participants came from research and academia, professional and voluntary health organizations, trade organizations, industry, and government. They developed dozens of ideas and recommendations which they prioritized into specific actions that could be realistically implemented by the coalition and other concerned groups. The result is an action plan that focuses on four priorities: (1) developing a national bone health alliance, (2) promoting bone health and preventing disease, (3) improving diagnosis and treatment, and (4) enhancing research, surveillance, and evaluation. A summary of these priorities and key strategies follows (Table 1) and the full report can be accessed at this web site: www.nof.org/professionals/ National_Action_Plan.htm [2].

To begin work on this plan, a steering committee has begun to engage a much larger number of interested and talented individuals in identifying specific, immediate, and long-term goals. Identifying the goals, many of which are already well known, is not sufficient. To bring about a coordinated and sustained effort to achieve the goals, human and financial resources are required. These are not the best of times to find funding and to engage individuals in an effort to improve the country's bone health, but they may not be the worst of times. All of us who work in the field of bone metabolism, as well as everyone who is interesting in improving the nation's health, has both a stake and an opportunity to participate. The steering committee asks all those who have already become involved and are passionate about this effort to continue to strengthen that effort both as individuals and as members of organizations or groups that are concerned about bone health. We also hope that those who have not yet become involved will read the national action plan and explore possible ways they can participate:

1. Read the plan.

2. Think about what you as an individual, as a member of a practice, and as a specialist can do under each of the four priorities.

3. Join us! Contact the Steering Committee of the National Action Plan for Bone Health at (202) 2232226 or nof@nof.org to express your interest in participating with others in these efforts.

\section{References}

1. U.S. Department of Health and Human Services (2004) Bone health and osteoporosis: a report of the surgeon general. US Department of Health and Human Services, Office of the Surgeon General, Rockville

2. The National Coalition for Osteoporosis and Related Bone Diseases (2009) National Action Plan for Bone Health: recommendations from the Summit for a National Action Plan for Bone Health. Washington, DC. c2009 [cited 2009 June 1]: Available from: http://www.nof.org/professionals/National_Action_Plan.htm 